\title{
Research on Construction and Evaluation System of eco-city_-Take Qingdao for Example
}

\author{
Yujie $\mathrm{Ge}^{1}$, \\ ${ }^{1}$ Qingdao Vocational and Technical College of Hotel \\ Management, \\ Qingdao, China
}

\author{
Lin Zhao ${ }^{2}$, \\ ${ }^{2}$ Ocean University of China, \\ Qingdao, China
}

\author{
Yibing $\mathrm{Xie}^{3}$, Weilin Huang ${ }^{3}$ \\ ${ }^{3}$ Qingdao Vocational and Technical College of Hotel Management, \\ Qingdao, China
}

\begin{abstract}
With the emergence of various ecological crisis, changes in people's values as well as the impact of a variety of "green" ideological trend, people pay more and more attention to the construction of ecological and livable city. At present, the research on Eco-city has become one of the hot issues in the field of the urban planning and urban science research. Because "Research on Construction and Evaluation System of Eco-City" is the important content of ecological city theory system, so studying the theory has the important theoretical and realistic significance. SWOT analysis is used to analyze the condition of the ecological city construction in Qingdao in the paper. Evaluation System of Eco-City is preliminary built through the frequency statistics, on the basis of combining the related data from 2005 to 2012 in Qingdao, principal component analysis is used to longitudinal evaluate the development status of ecological city with Qingdao. Research and evaluation of Qingdao, has important practical significance for reasonable measuring the present condition of urban construction, improving the level of urban construction and promoting the construction of ecological city, at the same time also has a certain reference for the construction of other cities.
\end{abstract}

Keywords-Ecological City; Principal Component Analysis; Evaluation Index System.

\section{ANALYSIS ON THE CONSTRUCTION OF ECOLOGICAL CONDITIONS IN QINGDAO}

\section{A. S- Advantage analysis}

1) Obvious location advantage

Qingdao city is located in the Shandong peninsula the throat, has the natural advantage of location. In our planning "five vertical five horizontal" railway network in Qingdao is in the core region, eastern coastal "vertical" central zone. Qingdao surrounding "inland sea" Jiao zhou Bay, Southeast brink of the Yellow Sea natural geographical advantage, three facing the sea of the west coast of the Pacific Ocean makes Qingdao become an important international trade port and sea transport hub. Provide a good foundation for the rich marine resources and superior geographic advantages for Qingdao city to develop biomass energy, ocean energy, solar energy and other new energy. At the same time as the role of regional national aviation port, airport expansion, upgrade and the upcoming construction of Qing ha high iron, will provide favorable conditions for cohesion, strengthen regional cooperation and boost hinterland economy development for Qingdao enhancement, will also further enhance the comprehensive transportation hub of Qingdao city new position.

2) A significant advantage of talent and science

Qingdao talent resource intensive, has a large number of excellent marine science and technology, business management, tourism and professional technology and other aspects of the professional talents. Qingdao city marine science and technology talent to come out on top in the entire Shandong Peninsula, in the transformation of marine biotechnology, marine medicine $\mathrm{R} \& \mathrm{D}$ innovation and achievement has good prospects for development. Around the development of Qingdao City high-tech industry, will drive the other related industry in conjunction with the rise, development. Such as the Yellow Sea pharmaceutical research and development, production integration project together, development will drive the related industrial clusters of blue economy in Qingdao city.

3) The strength of the economy

Qingdao is a manufacturing industry and modern service industry more developed city, has Haier, Hisense, Tsingtao Brewery and some other listed international famous brands and enterprises, since the new century, the brand economy presents the development trend of high-tech, cluster. The development of the tourism industry, the financial sector and other service industry in recent years rapidly, greatly promoted the economic development of Qingdao city. Shows that the economic operation in 2013 in Qingdao City, Qingdao city in 2013 third industrial growth of 10.5\%, second of industrial growth of $10.2 \%$, per capita disposable income of urban residents increased by $9.6 \%$, people's living standards gradually improved, the overall economic development trend of steady growth. 


\section{B. W-Disadvantage analysis}

\section{1) Natural resources and environmental capacity con-} straints

With the development of the city, the regional population, resources and environmental pressure further highlighted the existing ecological wetland, forest system and other sensitive resources become less and less. Although Qingdao city is surrounded by water on three sides, lakes, rivers and numerous, but Qingdao is a city of serious water shortage. Qingdao's annual rainfall less than $700 \mathrm{~mm}$, freshwater resources per capita is 312 cubic meters, far below the national standard, belong to one of the very serious water shortage city. With the rise of the contradiction between urban development and the need of resources, environmental capacity is insufficient, the development of the city will be restricted to a certain extent.

2) The higher energy consumption, ecological resources damage

At present energy consumption is mainly coal, natural gas, petroleum and its products in Qingdao, along with the development and utilization of new energy and increase people's ecological consciousness, their share of consumption in the total energy consumption is showing a declining trend, but the consumption amount above scale enterprises and electricity consumption is still high, the consumption structure of high energy consumption in order to resource low reuse level has to Qingdao city environment brings certain negative influence.

3) Integrated transport system is not perfect, traffic pressure is great

After the development in recent years, Qingdao City, inner and outer traffic bottleneck has been basically ease. However, with the increase in the number of city population and vehicle, contradiction surge traffic flow and road infrastructure has lagged behind the increasingly prominent. Due to the underground passage of the main road and overpass less, greatly reduce the traffic speed. At the same time as less parking, at present Qingdao illegal free park vehicle phenomenon has seriously affected the normal traffic order. Qingdao should accelerate the improvement of city comprehensive transportation system, the development and utilization of fast promote the construction of threedimensional rapid transit and the city underground space, to improve the traffic situation of the city.

4) The single investment, less financing channels

Qingdao city infrastructure and the construction of public sector mainly relying on government investment, private capital and foreign investment proportion is very small, the construction of the huge funding gap. At the same time as the traditional ideas, policies, institutional constraints, the infrastructure industry barriers is not completely broken, the foreign capital and private capital into the industry to invest in the resistance is relatively large, the government financing channels for a single, not conducive to the construction, urban projects related to the development.

\section{O- Opportunity analysis}

1) Global capital, technology to speed up the transfer

With the trend of globalization speeding up, the development of regional economic integration and economic globalization quickly, between different countries and different between the regional capital, technology and other exchanges have become increasingly frequent, inject new vitality into the economic development. In 2011 the State Council approved the Shandong peninsula on the construction of the "Blue Economic Zone Development Plan", replied the "planning" will help Qingdao give full play to the existing location and resource advantages, at the same time, from the outside to obtain more favorable factors, better realize an industry to undertake and capital transfer. The implement of the plan will help Qingdao to form a new economic growth pole, Qingdao should take this opportunity to system and mechanism innovation and technological innovation as a driving force, give full play to local advantages, vigorously cultivate new and high-end industries, expand the regional development space.

2) Government support for the construction of ecological civilization

On the construction of a resource-saving and environment-friendly city, Qingdao introduced the "Qingdao eco city construction plan" in 2003, the environmental governance and environmental protection put in the first place. Eighteen clearly pointed out that the ecological civilization construction in a prominent position, the ecological civilization construction into the whole process of economic construction and social construction. At present, Shandong province is in the industrialization and urbanization phase of rapid development, the increasing need of economic development and resources and environment carrying capacity is insufficient for the increasingly acute contradictions between, in order to solve the problems in the course of urban development, the Shandong provincial government put forward the construction of ecological Shandong decision, which promoted the development of ecological city construction in to a certain extent.

3) Domestic and international experience in building successful reference

Abroad, Copenhagen, London, Tokyo, Singapore, and the new eco city, Tianjin city in domestic Tangshan Caofeidian port, great achievements have been made in ecological construction, can learn the advanced technologies and concepts in the construction of ecological city, and provide the reference for the construction of eco city in Qingdao city.

\section{T-Challenge analysis}

\section{1) The fierce regional competition}

With the development of economic globalization and regional economic integration advancement, more unstable factors to international trade friction and the development of the economy, exacerbating factors intercity, inter industry funds and personnel development and market space competition, if not actively respond to challenges, to accele- 
rate the pace of reform and development, will enhance the overall competitiveness of Qingdao city have influence on.

\section{2) Constrained resource contradiction}

At present, the overall development model of Qingdao is still in a state of expansion, has a strong dependence on investment. In the next period of time, with the increase of city population, industrialization, marketization and the city of Qingdao city to accelerate, intensity of consumption of resources and energy will continue to increase, and the supply of energy resources pressure will continue to increase. If the contradiction between cannot handle resources, the need of energy supply constraints and urban development, urban development will be constrained.

3) The industrial structure is in transformation

From the current Qingdao city industrial structure situation, petroleum, chemical industry, coal and other high energy consuming enterprises still occupy a considerable share in Qingdao market. The industry is a high energy consumption industry, will bring the negative influence to the development of city economy in a certain extent. In finance, consulting and other services industries of the third industrial development is slow, and the proportion is low, it will hinder the development of the city to a certain extent. Generally speaking, the Qingdao city industrial structure is not reasonable, it shall require the transformation.

Aiming at the analysis of advantage and disadvantage, the opportunities and challenges of eco city construction in Qingdao City, Qingdao should seize the opportunity and meet the challenges in the process of development, make full use of and digging their own advantages, actively promoting the construction of ecological city.

First of all, should respond positively to the national strategy, seize the development opportunity, into the world economy big circulation. Should make full use of external opportunities and its location advantage, talent advantage and scientific and technological advantages, actively learn from the advanced experience of domestic and international ecological city construction, promote the construction of ecological city of Qingdao process. Secondly, to face their own shortcomings, the optimization of the industrial structure, strengthen industrial cooperation, realize the complementary industries. Adjust industrial layout and energy structure, improving energy efficiency, and actively guide the high pollution, high emission enterprises take the recycling economy mode, the promotion of new energy development and utilization, to encourage the development of new industries and high-tech industries, make full use of science and technology, talent and ecological resource advantage of ecological city construction. Finally, to enhance the public awareness of the ecological and environmental awareness, strengthen the city's environmental remediation. Gradually improve the city infrastructure construction, improve the city sewage treatment capacity, improve the public traffic efficiency, improve the quality of people's life. At the same time to actively explore the construction of urban infrastructure financing channels, widely to attract domestic and international idle funds and advanced technology, to guide the funds for urban construction services, in order to achieve the sustainable development of infrastructure projects.

\section{THE OPTIMIZATION OF COMPREHENSIVE EVALUATION INDEX SYSTEM OF ECO CITY AND BASED ON PRINCIPAL COMPONENT ANALYSIS}

The quantitative data mostly derived from the "statistical yearbook of Shandong province" and "Qingdao Statistical Yearbook" in this paper, little part is obtained by access to online information, some of the original data can be directly used for evaluation, also need some data obtained through calculation, qualitative data mainly through evaluation to determine the (usual 60, good 70, better80, very good 90).

This paper selects 2005-2012 in Qingdao City, analyzed data, through access to statistical yearbook, Qingdao statistical information network, Qingdao City Environmental bulletin and other channels, the obtained data collation, specific see table two. As the evaluation index is more, here on eco economic system, social ecological system and ecological environment system of data processing.

\section{A. The comprehensive evaluation of ecological environment system}

The original data of ecological environment system is standardized, the standardized processing results see table five. Characteristic root, variance contribution through the SPSS software to calculate the matrix can be obtained after the rate and cumulative contribution rate, shown in table 1.

TABLE 1. EIGENVALUE AND CONTRIBUTION RATE OF ECOLOGICAL ENVIRONMENT SYSTEM.

\begin{tabular}{cccc}
\hline \multirow{2}{*}{ Ingredients } & \multicolumn{3}{c}{ Initial eigenvalue } \\
\cline { 2 - 4 } & Total & Variance \% & Cumulative \% \\
\hline 1 & 9.451 & 63.008 & 63.008 \\
\hline 2 & 2.455 & 16.369 & 79.377 \\
\hline 3 & 1.286 & 8.576 & 87.953 \\
\hline
\end{tabular}

From table 2-7 can be seen when the number of principal component is 3 , the cumulative contribution rate has reached $87.953 \%$, more than $85 \%$, according to the principal component extraction principle, can choose 3 principal components of F1, F2, F3, a comprehensive reflection of Qingdao city in recent years the integrated development environment of ecological construction in the construction of ecological city development level. Load matrix of the three principal components shown in table 2. 
TABLE 2. PRINCIPAL COMPONENTS LOAD MATRIX OF ECOLOGICAL ENVIRONMENT SYSTEM.

Component load matrixa

\begin{tabular}{|c|c|c|c|}
\hline \multirow[t]{2}{*}{ Ingredients } & \multirow[b]{2}{*}{1} & \multirow[b]{2}{*}{2} & \multirow[b]{2}{*}{3} \\
\hline & & & \\
\hline $\begin{array}{l}\text { D1Coverage rate of afforestation } \\
\text { in developed area }\end{array}$ & 0.907 & 0.03 & 0.092 \\
\hline D2 The per capita arable land & -0.221 & -0.92 & -0.225 \\
\hline D3 SO2 emission intensity & -0.9440 & 0.297 & 0.108 \\
\hline D4 COD emission intensity & 0.438 & 0.834 & $4 \quad-0.16$ \\
\hline $\begin{array}{l}\text { D5 The urban air quality and } \\
\text { excellent rate }\end{array}$ & 0.624 & -0.211 & 0.694 \\
\hline $\begin{array}{l}\text { D6 City regional environmental } \\
\text { noise, the average sound level }\end{array}$ & 0.87 & 0.116 & 0.339 \\
\hline $\begin{array}{l}\text { D7 Coverage area noise } \\
\text { compliance areas built }\end{array}$ & 0.721 & -0.332 & 0.14 \\
\hline $\begin{array}{l}\text { D8The standard rate of city } \\
\text { centralized drinking water source } \\
\text { water quality }\end{array}$ & 0.915 & 0.024 & -0.085 \\
\hline $\begin{array}{l}\text { D9Coastal waters functional area } \\
\text { compliance rate }\end{array}$ & 0.727 & 0.492 & -0.438 \\
\hline $\begin{array}{l}\text { D10 Ecological consciousness } \\
\text { popularity rate }\end{array}$ & 0.948 & 0.08 & -0.151 \\
\hline $\begin{array}{l}\text { D11 The public environmental } \\
\text { satisfaction }\end{array}$ & 0.852 & 0.153 & -0.073 \\
\hline $\begin{array}{l}\text { D12 Centralized treatment of } \\
\text { urban wastewater }\end{array}$ & 0.916 & -0.341 & -0.07 \\
\hline $\begin{array}{l}\text { D13The utilization rate of } \\
\text { industrial solid waste disposal } \\
\text { waste disposal }\end{array}$ & 0.857 & -0.405 & -0.224 \\
\hline $\begin{array}{l}\text { D14 The recycling rate of } \\
\text { industrial water }\end{array}$ & 0.903 & 0.215 & 0.381 \\
\hline $\begin{array}{l}\text { D15Environmental protection } \\
\text { investment accounted for the } \\
\text { proportion of GDP }\end{array}$ & -0.684 & 0.24 & 0.382 \\
\hline $\begin{array}{l}\text { Extraction method: principal comp } \\
\text { a. The extraction of } 3 \text { components. }\end{array}$ & bonent. & & \\
\hline
\end{tabular}

It is seen from table 2-8 can, phase relations in the first principal component and D1 built-up area green coverage rate, D3SO2 emission intensity, D8 city of centralized drinking water source to water quality compliance rate, ecological consciousness, D12 D10 the popularization rate of city life sewage centralized treatment rate, D14 industrial water recycling rate index number reached more than 0.9 , can be seen in the first the main composition and environmental ecological construction of all aspects of the relationship between the larger, could reflect the overall level of ecological environmental construction. Second principal components are related to D2, D4COD, area of farmland of average per capita emission intensity index, ecological status mainly reflect the current Qingdao city. Third principal components are related to D5 urban air quality excellent rate, function of D9 nearshore zones compliance rate and other indicators, mainly reflects the resistance ability of the environment pollution of ecological environment construction in Qingdao city.

The standardized data generation into the composition formula, the comprehensive score can get the score of each principal component and the ecological environment system, specifically shown in table 3 .

TABLE 3. SCORE OF EVERY PRINCIPAL COMPONENT OF ECOLOGICAL ENVIRONMENT SYSTEM AND THE COMPREHENSIVE DEVELOPMENT INDEX.

\begin{tabular}{ccccc}
\hline & $\mathrm{f} 1$ & $\mathrm{f} 2$ & $\mathrm{f} 3$ & $\mathrm{~F} 3$ \\
\hline 2005 & -1.519 & 1.204 & 0.899 & -0.683 \\
2006 & -0.890 & 0.547 & -0.264 & -0.494 \\
2007 & -0.523 & -0.882 & -0.498 & -0.517 \\
2008 & -0.369 & -1.434 & 0.131 & -0.456 \\
2009 & 0.127 & -1.026 & -0.428 & -0.124 \\
2010 & 0.828 & 1.025 & -1.582 & 0.554 \\
2011 & 1.029 & 0.566 & -0.051 & 0.737 \\
2012 & 1.310 & 0.009 & 1.780 & 0.979 \\
\hline
\end{tabular}

According to the change tendency of each principal component score and comprehensive score can obtain the corresponding graph, as shown in figure 1 .

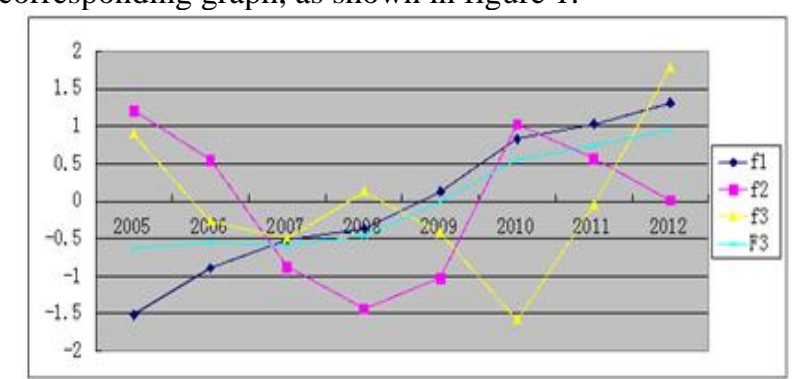

Figure 1. In 2005-2012 the ecological environment of the principal components and the overall development index trend chart of Qingdao.

As you can see in Figure 2-3 the first principal components showed a rising trend, show that the ecological level of Qingdao city in the overall state of gradually improve. But the second and the third principal component of total fluctuations in the state, and showing a trend that is not harmonious, Qingdao city in the construction of ecological environment in the process of environmental pollution resistance ability is not stable, should increase the environmental protection and management.

Generally speaking, with the development of economy and society in Qingdao City, and the environmental awareness of the popularization and development of ecological construction of capacity of the environment is improving gradually. But along with the need of social development, development of environmental resources, urban use will continue to increase, we should deal with the relationship between development and environment.

\section{B. The comprehensive evaluation of ecological economic system}

Similarly, the original data on the ecological economic system of standardization. The standardized data generation into the composition formula, get the comprehensive scores of each principal component and the ecological economic system. According to the change tendency of each principal component score and comprehensive score can obtain the corresponding graph, as shown in figure 2. 


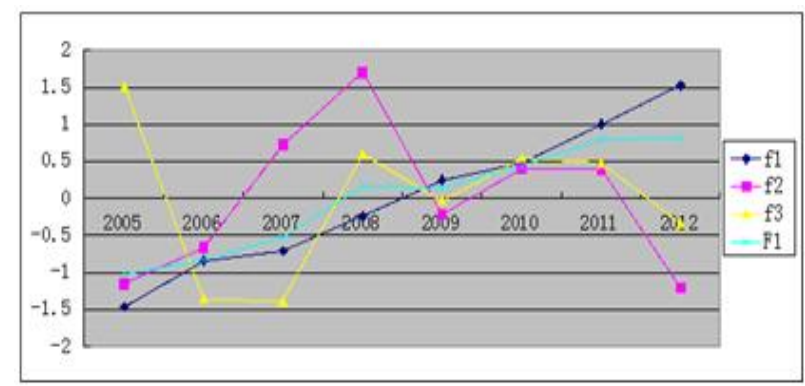

Figure 2. Qingdao ecological economy 2005-2012 principal components and overall development index trend chart.

As you can see in Figure 2 scores of the first principal component continued to rise, show that the Qingdao city economic development scale and speed of development in the continued ascent. Especially the great leap forward economic development since 2008. The second and the third principal component development is not stable, the upward trend before 2008, 2008 after declining trend, that with the development of economy, the economic structure has been unable to adapt to the development of the economy of scale and speed of development, economic structure needs to change.

Generally speaking, the construction of ecological economy of Qingdao city in the ability to continuously improve. But should speed up the adjustment of economic structure, focus on the development of high-tech industry, small and medium-sized enterprises and tourism, only the continuous improvement of science and technology investment, encourage the development of small and mediumsized enterprises, in order to gradually realize the adjustment of economic structure, to realize ecological economic construction.

\section{The comprehensive evaluation of ecological social system}

Similarly, the original data of eco social system is standardized, the standardized data generation into the composition formula, get the comprehensive scores of each principal component and the social ecological system. According to the change tendency of each principal component score and comprehensive score can obtain the corresponding graph, as shown in figure 3.

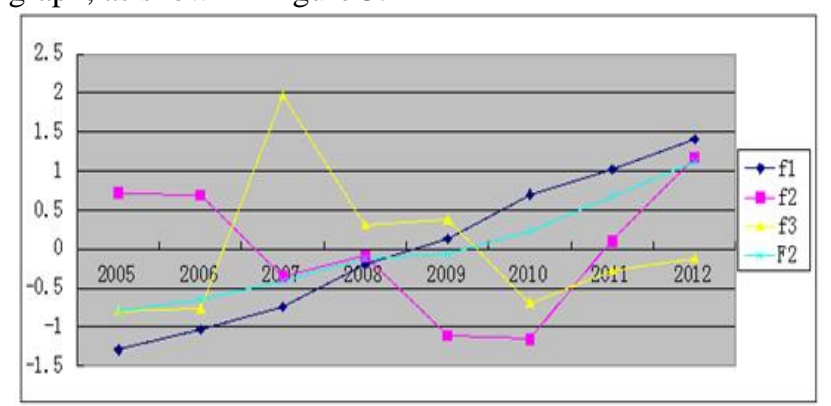

Figure 3. The variation tendency of the social ecological 2005-2012 principal components and overall development index map of Qingdao City.
As can be seen from the above 3, the first principal component score curve showed a clear upward trend, the second and the third principal components have certain fluctuation. Before 2010, the second and the third principal component basically show a downward trend, which indicates that the social construction of Qingdao city investment insufficiency in the aspect of science education and social security. Showing a clear upward trend after 2010, shows that with the economic development of Qingdao, the government gradually pay more attention to the social construction investment, but the development was slow, needs to be strengthened.

Generally speaking, Qingdao eco city society construction showed a rising trend, but the volatility is relatively large, stability, the construction of the ecological community persistence needs to be strengthened. Therefore, in the construction of the ecological society of Qingdao city should strengthen the social security and science and technology input, and gradually perfect the construction of the ecological society.

\section{CONCLUSIONS}

Qingdao City as the ecological city in the 2005-2012 years in 8 year construction level is increased year by year. Especially after 2008, continued to accelerate, enhance the capacity building of eco city in Qingdao city. From the analysis of single factor before the show was mainly due to Qingdao city's economic, social and environmental aspects of construction development, especially in Qingdao in 2008 to participate in the Olympics, this development to the city of Qingdao has created a good opportunity.

Comprehensive above analysis, Qingdao city from the following several aspects to promote the construction of ecological city. In the ecological and economic aspects, focus on the development of high-tech industry, small and medium-sized enterprises and tourism, continuous investment to improve the technology, and actively adjust the industrial structure, and gradually realize the transformation of economic structure. In the ecological society, should gradually improve the infrastructure construction, strengthen the social security, science and technology investment, provide public urban sense of ownership and on the city's satisfaction. In the ecological environment should increase the protection of the environment and management strength, improve the ecological consciousness of citizens, and gradually realize the ecological environment. 


\section{REFERENCES}

[1] Qingdao Municipal Bureau of Statistics. Qingdao statistical yearbook(2006-2013),China Statistics Press(2006-2013).

[2] http://www.statsqd.gov.cn/statsqd/index/index.shtml ,Statistical information network of Qingdao City.

[3] http://cms.qingdao.gov.cn/n14746/n14836/n14873/n14876/c6180573/c ontent.html, Qingdao city government network-Qingdao City Environment Bulletin.

[4] Qiong Wu, RUsong Wang. City index system and evaluation of ecological method. Journal of ecology,2005,(8).

[5] Qingji Shen. City ecology and environment of the city. Tongji University press,1998.

[6] Guangyu Huang. The development of ecological city planning and construction Chinese. City environment and city ecological, 2001,(3). 